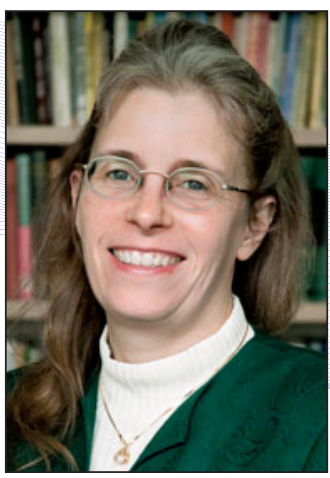

Susan Trolier-McKinstry 2017 MRS President

\title{
Charting the future direction of the Society
}

A warm greeting to all of you in 2017. The Materials Research Society (MRS) has a rich tradition of excellence and works to ensure a vibrant future for our interactive, global community of materials researchers. It is my distinct honor and pleasure to serve as the 2017 President of MRS; I look forward to meeting and working with many of you over the course of the upcoming year.

As we move into 2017, there are several upcoming activities that I would like to highlight, including our Spring Meeting and a yearlong effort on strategic planning for the Society.

The 2017 MRS Spring Meeting Chairs Christopher J. Bettinger, Stefan A. Maier, Alfonso H.W. Ngan, W. Jud Ready, and Eli A. Sutter are working with over 250 symposium organizers and headquarters staff to craft a dynamic Meeting centered around five topical clusters:

- Characterization, Theory, and Modeling: These symposia will describe recent advances in materials simulation over length scales, with an emphasis on the tight coupling between modeling, experiment, and the development of novel characterization tools to drive the development of novel materials.

-Electronic Devices and Materials: These symposia will focus on the application of materials to diverse areas in quantum technologies, photovoltaics, future optoelectronic circuits, plasmonics, metamaterials, and neurobiology.

- Energy Storage and Conversion: One way in which materials research can improve the quality of human life around the planet is through the development of materials for power generation, energy storage, and efficient transmission. This cluster will address all of these areas.

- Nanomaterials: The manner in which materials' properties can be modulated at small scales and low dimensionalities offers significant opportunities both in materials exploration and in a wide range of applications. This cluster will span the spectrum from fundamental to applied materials research.

- Soft Materials and Biomaterials: This cluster concentrates on the exploration and development of advanced polymers, polymeric biomaterials, bioelectronics, materials for immunology, membranes, soft robotics, neural interfaces, multifunctional fibers, and biomineralization. 
As always, a broad range of activities and special events, such as the MRS Career Fair, plenary and award talks, and broader impacts programming, will also contribute to the "community" atmosphere. And our new venue, the Phoenix Convention Center, allows us to host all of these events under one roof, enhancing the interdisciplinary nature of the MRS Meeting and affording expanded networking opportunities.

Meeting attendees will also find Phoenix to be an excellent host city. With incredible weather and accommodations, as well as a wide array of restaurants, nightlife, cultural, and sporting events just steps away from the Convention Center, Phoenix will provide a refreshing mix of science, sun, and scenery. We look forward to seeing you April 17-21 for the 2017 MRS Spring Meeting. More information can be found at www.mrs.org/ spring2017.

A second key area to which I would like to draw your attention is strategic planning. In 2016, our operating committees, board of directors, and headquarters staff evaluated the current status of MRS and its programs. In 2017, we'll be looking at the scope of our activities, from meetings and publications, to outreach, to assess where we are as a Society and how we can better position ourselves for the future. Society leadership values and seeks your input into the process. To that end, we'll conduct a membership survey in February and focus group sessions at the 2017 MRS Spring Meeting. Matt Copel, chair of the MRS Planning Committee, and I would greatly appreciate your feedback, as it will significantly influence the direction of the 2017 MRS Strategic Planning Meeting in July. On behalf of the MRS Board of Directors, our volunteers, and our staff, I thank you for your help as we chart the future direction of our Society.

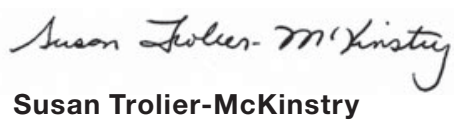

2017 MRS President 